\title{
A prospective randomised study comparing the current surgical informed consent form with a modified, pre- printed consent form
}

\author{
Bhuvaneswari Krishnamoorthy ${ }^{*}$, Kok-Hooi Yap ${ }^{1}$, William R Critchley ${ }^{2}$, Nair ${ }^{1}$, N Devan $^{1}, \mathrm{~J} \mathrm{Barnard}^{1}$, Ann Caress ${ }^{3}$ and Paul D Waterworth $^{1}$ \\ ${ }^{1}$ Department of Cardiothoracic Surgery, University Hospital of South Manchester NHS Foundation Trust, Manchester, UK \\ ${ }^{2}$ The Transplant Centre, University Hospital of South Manchester NHS Foundation Trust, Manchester, UK \\ ${ }^{3}$ School of Nursing and Midwifery, The University of Manchester, Manchester, UK, M13 9WL
}

\begin{abstract}
Background: Patient understanding is a fundamental requirement for the consent process, yet current UK Department of Health consent forms rely on handwritten explanations on admission prior to cardiac surgery. A pre-printed consent form containing pertinent information about the planned procedure and its associated benefits/risks may benefit in patient retention of information.
\end{abstract}

Trial design: Randomised study using a pre-test/post-test design in which participants completed a questionnaire prior to providing consent and following surgery.

Methods: 100 patients scheduled for coronary artery bypass surgery were recruited and randomised by computer into two groups receiving either the current standard handwritten consent form (group 1) or a modified pre-printed consent form (group 2).

Objective: To assess whether a standardised, pre-printed consent form improves patient information retention and experience of the consent process.

Results: No significant differences in demographics or pre-consent questionnaire data were observed between groups. A greater proportion of patients could identify $(62.0 \%$ vs. $30.0 \%, p=0.011)$ and understand their surgical procedure $(66.0 \%$ vs. $20.0 \%, p=0.001)$ in group 2 compared to group 1 . Group 2 exhibited greater understanding of the benefits $(72.0 \%$ vs. $8.0 \%, \mathrm{p}<0.001)$ and risks $(82.0 \%$ vs. $10.0 \%, \mathrm{p}<0.001)$ of the surgery and indicated greater satisfaction with the consent process post-operatively ( $94.29 \%$ vs. $85.22 \%, \mathrm{p}<0.001)$ compared to group 1 .

Conclusion: This study highlights the importance of a written explanation on the consent form, which encourages greater patient understanding and aids in shared decision making between the surgical team and the patient.

\section{Introduction}

Informed consent has two main principles, first to respect and promote patients' autonomy and second to protect them from potential harm [1]. The consent form itself also acts as a procedural record of the discussion between the surgical team and the patient. The United Kingdom Department of Health insists patients need to have an understanding of their diagnosis, prognosis, the nature and purpose of any intervention, as well as the benefits and risks of the surgical procedure [2]. The existing literature also suggests that the modification of the content, writing style, format or length of the consent form is no more successful than other approaches that focus on improving comprehension [3]. Cardiac surgery requires a robust consent process for informed consent to be given. This involves providing the patient with appropriate information regarding the nature of the procedure, intended benefits and possible risks. At present, these are explained to all elective patients in the outpatient clinic by a consultant surgeon approximately 4 weeks prior to surgery. The formal consent form is completed on admission, with a verbal explanation usually provided by the specialist nurse. However, it is clear from previous studies that there is room for improvement in patients' understanding of their scheduled cardiac procedure $[4,5]$.

Currently, the Department of Health consent form must have the procedure, benefits and risk filled out manually for each patient. This leads to significant variation between individual members of the surgical team with regards to their explanation of the surgical procedure. We aimed to produce a more standardised and reproducible consent form to be completed by specialist surgical with the intention of improving patients' retention of knowledge.

Cardiac surgery consists of many varied procedures, with different associated benefits and complications. As coronary artery bypass surgery has fewer complications than many other cardiac surgical procedures, we decided to perform a pilot study within this cohort to assess the effect of a pre-printed consent form. The primary aim of this study was to compare the current Department of Health consent form with a standardised, pre-printed consent form, with regards to

Correspondence to: Bhuvaneswari Krishnamoorthy, Lead Surgical Nurse Practitioner, Cardiothoracic surgery, University Hospital of South Manchester NHS Foundation Trust, Manchester, UK, M23 9LT, Tel: 0044-161-291-2078; Fax: 0044-161-291-5024; E-mail: bhuvaneswari.bibleraaj@uhsm.nhs.uk

Key words: coronary artery bypass, saphenous vein, cardiac surgery, consent forms, patient satisfaction

Received: July 16, 2016; Accepted: August 19, 2016; Published: August 22, 2016 
the effect on patients' understanding of their surgery and its associated benefits and risks. This study also aimed to assess and compare patient satisfaction with the consent process using the two different forms.

\section{Methods}

\section{Patient recruitment and eligibility criteria}

A prospective pilot randomised study of 100 consecutive patients undergoing elective or urgent coronary artery bypass grafting was performed at a single UK hospital, between November 2011 and October 2012. Patients were considered eligible for recruitment if they were scheduled for elective or urgent coronary artery bypass grafting, were aged 18 years or over and were able to provide informed consent to enrol into the study. Sample size was determined by an independent statistician. Computerised block randomisation was used to allocate patients into two groups, and allocations were concealed in sequentially numbered sealed envelopes. The sealed envelope was given to the research team just before the consenting process by the theatre co-ordinator. Group 1 were consented using the current Department of Health consent form (Figure 1), while group 2 were consented using the new, standardised consent form (Figure 2). A pretest/post-test study design was utilised in which all patients were asked to complete a consent questionnaire prior to and following surgery.

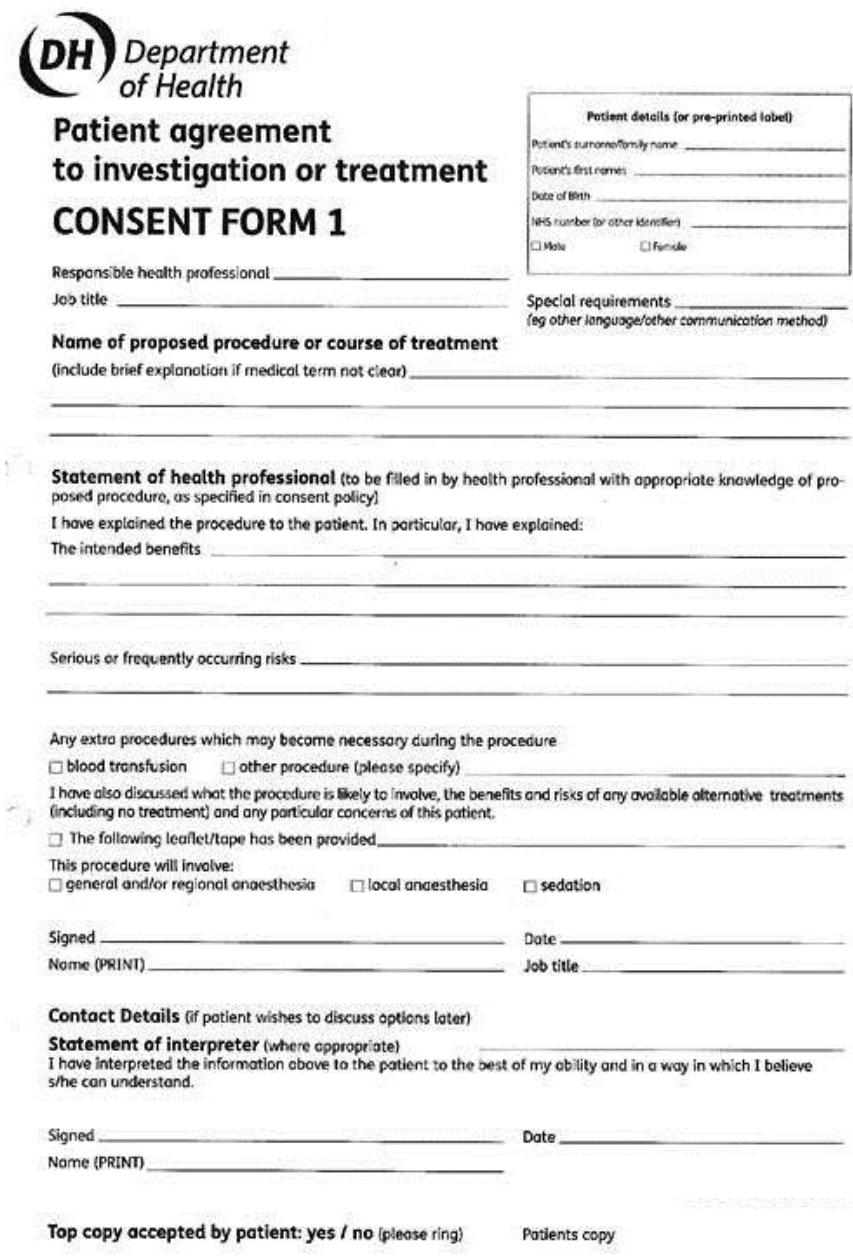

Figure 1. This figure illustrates the current Department of Health consent form. Notably, this form is designed as a general guide to the major points that should be expressed during the consent process, and as such has significant gaps for the entry of information related to the procedure. This promotes wide variation between individuals.

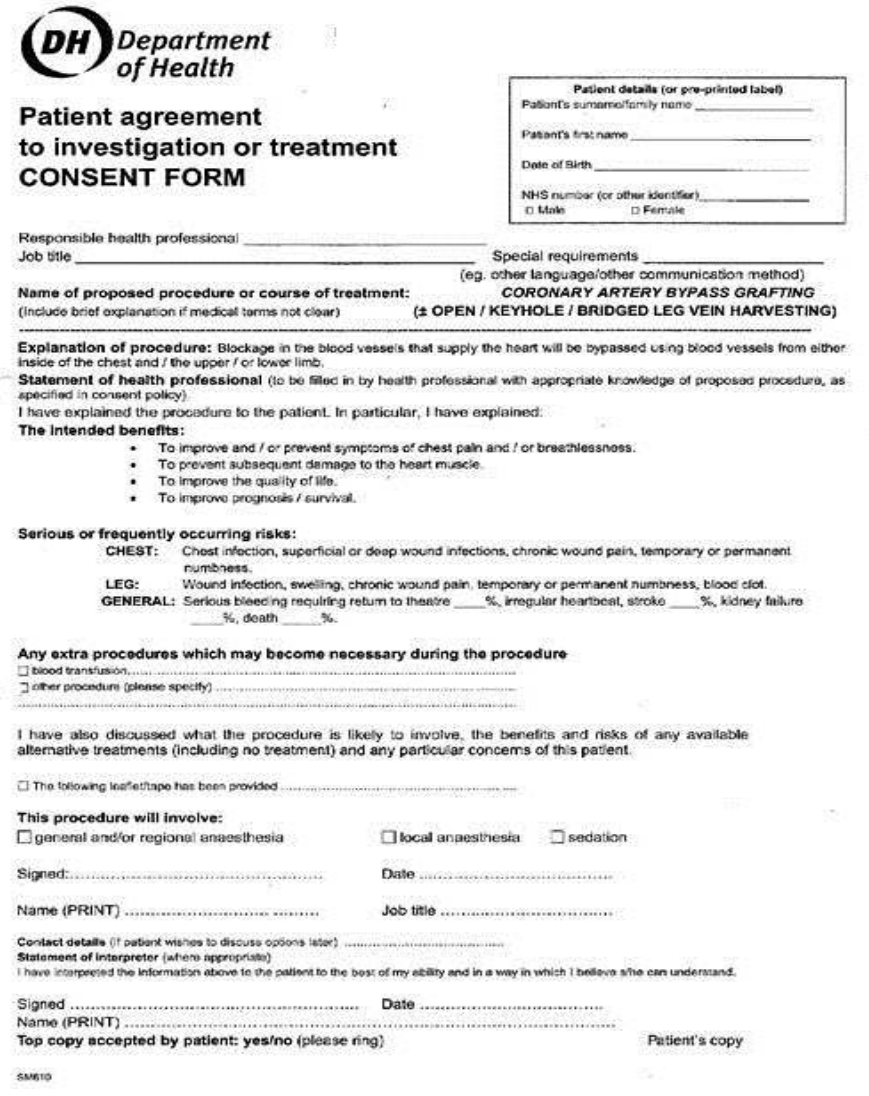

Figure 2. This figure illustrates the modified Department of Health consent form. This pre-prepared consent form clearly states the procedure as well as the associated benefits and risks, reducing the amount of variation in the information related to the patient.

No changes to the methods were required following commencement of the study. Patients were enrolled by a clinically trained surgical nurse practitioner. All patients were appropriately counselled and provided informed written consent.

\section{Objectives}

The primary aim of this study was to determine whether the use of a pre-printed consent form influenced patient understanding of their surgical procedure and its associated risks and benefits. The secondary aim of the study was to compare patient satisfaction with the consent process using the standard UK Department of Health form and the modified, pre-printed form.

\section{Data collection}

The preoperative questionnaire was given to all patients in both groups before consent was taken. All elective patients visited the outpatient department to see the Consultant Cardiac Surgeon approximately 4 weeks prior to surgery. Urgent-in-house patients were visited by the Consultant surgeons on the preoperative ward to discuss their surgery. All patients were also provided with a cardiac information booklet prior to their surgery. The booklet included preoperative, intraoperative and postoperative information regarding their surgery. The patients were requested to score their understanding of their surgical procedure before providing consent and postoperatively. They were also asked to list the benefits and risks of their surgery. The post-surgery consent questionnaires were handed over to the patient on their day of discharge which was approximately 5-7 
days after surgery. Patient responses to each question were categorised based upon their level of understanding of the procedure. The number of relevant aspects that could be relayed back to the clinician in each question was recorded as " $0-1$ ", " $2-3$ " or “ 4 or more", reflective of poor, moderate and good understanding.

\section{Patient satisfaction}

Patients were requested to indicate their satisfaction level of the consent process. A validated visual analogue scale was utilised to register each score [6], which involved drawing a mark on a $100 \mathrm{~mm}$ line, where $0 \mathrm{~mm}$ indicated no satisfaction and $100 \mathrm{~mm}$ indicated complete satisfaction.

\section{Statistics}

All statistical analysis was performed using the IBM SPSS statistics package version 20 (IBM Corporation, New York, USA). The distribution of data was determined on the basis of mean, standard deviation, skewness and kurtosis values. Patient age was compared between groups using the independent $\mathrm{T}$ test. Patient satisfaction was compared between groups using the Mann-Whitney U-test. Categorical data was assessed using the chi-squared test. Statistical significance was accepted when $\mathrm{p}<0.05$.

\section{Results}

\section{Recruitment and assignment of patients}

Patients were recruited from the cardiac surgery annual waiting list. A total of $n=166$ patients provided consent to enrol into the study. Of these, $n=124$ patients were recruited and assigned to a group. A total of $n=4$ and $n=7$ from groups 1 and 2 respectively were lost to followup due to non-completion of the post-operative questionnaire. The study was ceased when $n=50$ patients from each group had completed both questionnaires. The remaining $\mathrm{n}=13$ patients were scheduled for surgery following completion of the study and were therefore not included.

\section{Demographics}

No statistically significant differences in patient demographics or pre-surgery consent questionnaire results were observed between groups. Equivalence of the two study groups is demonstrated in table 1.

\section{Pre-consent questionnaire}

The results of the pre-surgery consent questionnaire demonstrated that most of the patients in both groups were moderately able to name and understand the surgical procedure (Table 2). Furthermore, most patients were also able to explain 2-3 benefits and risks of their surgery. No significant difference was observed between the groups.

\section{Post-surgery consent questionnaire}

A significantly greater proportion of patients demonstrated a good understanding of their procedure in the modified consent form group than those receiving the standard form following surgery $(20.0 \%$ vs. $66.0 \%, \mathrm{p}=0.001)$. Patients also demonstrated greater understanding of the different vein harvesting techniques $(71.0 \%$ vs. $50.0 \%, \mathrm{p}=0.031)$ when the modified consent form was used compared to standard consent form. Group 2 also exhibited greater understanding of the benefits $(72.0 \%$ vs. $8.0 \%, \mathrm{p}<0.001)$ and risks $(82.0 \%$ vs. $10.0 \%, \mathrm{p}<0.001)$ of the procedure (Table 3 ).

\section{Patient satisfaction}

The patients in group 2 expressed greater satisfaction with the consent process post-operatively compared to group 1 (mean [95\% confidence interval]: $94.29 \%$ [91.60-96.97] vs. $85.22 \%$ [80.42-90.03], $\mathrm{p}<0.001$ ) (Figure 3).

\section{Discussion}

The informed consent process helps to identify and respect patients' best interests by giving each individual patient the opportunity to decide autonomously what his/her best options are with regards to the planned surgical procedure. However, in order to aid their decision, surgical patients require accurate information and appropriate guidance with

Table 1. Demographics between the two groups.

\begin{tabular}{|c|c|c|c|c|}
\hline \multicolumn{2}{|c|}{ Variable } & Standard consent form $(n=50)$ & Modified consent form $(n=50)$ & P-value \\
\hline \multicolumn{2}{|c|}{ Age $($ mean \pm SD) } & $65.48 \pm 9.66$ & $66.51 \pm 8.88$ & 0.854 \\
\hline \multirow[t]{2}{*}{ Sex } & Male & $42 / 50(84 \%)$ & $36 / 50(72 \%)$ & \multirow[t]{2}{*}{0.227} \\
\hline & Female & $8 / 50(16 \%)$ & $14 / 50(28 \%)$ & \\
\hline \multirow[t]{3}{*}{ Type } & Elective & $38 / 50(76 \%)$ & $29 / 50(58 \%)$ & \multirow[t]{3}{*}{0.088} \\
\hline & Urgent & $12 / 50(24 \%)$ & $21 / 50(42 \%)$ & \\
\hline & Emergency & $0 / 50(0 \%)$ & $0 / 50(0 \%)$ & \\
\hline
\end{tabular}

This table demonstrates the demographics of patients assigned to each group with no significant differences. There was a trend toward an increased proportion of patients undergoing urgent surgery in group 2 compared to group 1.

Table 2. Pre-test understanding of patient between two groups.

\begin{tabular}{|l|c|c|c|c|c|c|}
\hline \multirow{2}{*}{ Variable } & \multicolumn{4}{|c|}{ Level of understanding } \\
\cline { 2 - 6 } & \multicolumn{2}{|c|}{ Standard Consent Group (n=5) } & \multicolumn{2}{|c|}{ Modified Consent Group (n=50) } \\
\cline { 2 - 6 } & Poor & Moderate & Good & \multicolumn{2}{|c|}{ Poor } & \multicolumn{2}{|c|}{ Moderate } \\
\hline Able to name the procedure & $6 / 50(12 \%)$ & $36 / 50(72 \%)$ & $8 / 50(16 \%)$ & $2 / 50(4 \%)$ & $37 / 50(74 \%)$ & $11 / 50(22 \%)$ \\
\hline Patient understanding of the procedure & $6 / 50(12 \%)$ & $35 / 50(70 \%)$ & $9 / 50(18 \%)$ & $7 / 50(14 \%)$ & $33 / 50(66 \%)$ & $10 / 50(20 \%)$ \\
\hline Patient understanding of graft location & $11 / 50(22 \%)$ & $27 / 50(54 \%)$ & $12 / 50(24 \%)$ & $4 / 50(8 \%)$ & $29 / 50(58 \%)$ & $17 / 50(34 \%)$ \\
\hline $\begin{array}{l}\text { Standard of explanation of surgical } \\
\text { benefit by doctors }\end{array}$ & $14 / 50(28 \%)$ & $33 / 50(66 \%)$ & $3 / 50(6 \%)$ & $11 / 50(22 \%)$ & $35 / 50(70 \%)$ & $4 / 50(8 \%)$ \\
\hline $\begin{array}{l}\text { Standard of explanation of surgical risk } \\
\text { by doctors }\end{array}$ & $19 / 50(38 \%)$ & $29 / 50(58 \%)$ & $2 / 50(4 \%)$ & $21 / 50(42 \%)$ & $25 / 50(50 \%)$ & \\
\hline
\end{tabular}

This table illustrating the similarity in pre-consent questionnaire data between standard and modified consent form groups. 
Table 3. Post-test understanding of patients between two groups.

\begin{tabular}{|c|c|c|c|c|c|c|c|}
\hline \multirow{3}{*}{ Variable } & \multicolumn{6}{|c|}{ Level of understanding } & \multirow{3}{*}{ P-value } \\
\hline & \multicolumn{3}{|c|}{ Standard Consent Group $(\mathrm{n}=\mathbf{5 0})$} & \multicolumn{3}{|c|}{ Modified Consent Group $(\mathrm{n}=\mathbf{5 0})$} & \\
\hline & Poor & Moderate & Good & Poor & Moderate & Good & \\
\hline $\begin{array}{l}\text { Patient understanding of the } \\
\text { benefits of surgery }\end{array}$ & $4 / 50(8 \%)$ & $42 / 50(84 \%)$ & $4 / 50(8 \%)$ & $0 / 50(0 \%)$ & $14 / 50(28 \%)$ & $36 / 50(72 \%)$ & $\mathrm{p}<0.001$ \\
\hline $\begin{array}{l}\text { Patient understanding of the } \\
\text { risks of surgery }\end{array}$ & $10 / 50(20 \%)$ & $35 / 50(70 \%)$ & $5 / 50(10 \%)$ & $0 / 50(0 \%)$ & $9 / 50(18 \%)$ & $41 / 50(82 \%)$ & $\mathrm{p}<0.001$ \\
\hline $\begin{array}{l}\text { Patient explanation of the } \\
\text { surgical procedure }\end{array}$ & $6 / 50(12 \%)$ & $34 / 50(68 \%)$ & $10 / 50(20 \%)$ & $2 / 50(4 \%)$ & $15 / 50(30 \%)$ & $33 / 50(66 \%)$ & $\mathrm{p}=0.001$ \\
\hline $\begin{array}{l}\text { Patient understanding of } \\
\text { the differences between vein } \\
\text { harvesting techniques }\end{array}$ & $25 / 50(50 \%)$ & $\begin{array}{l}0 / 50 \\
(0 \%)\end{array}$ & $25 / 50(50 \%)$ & $15 / 50(30 \%)$ & $\begin{array}{l}0 / 50 \\
(0 \%)\end{array}$ & $35 / 50(70 \%)$ & $\mathrm{p}=0.031$ \\
\hline
\end{tabular}

This table illustrating the difference in understanding at the time of discharge between patients in the standard and modified consent form groups.

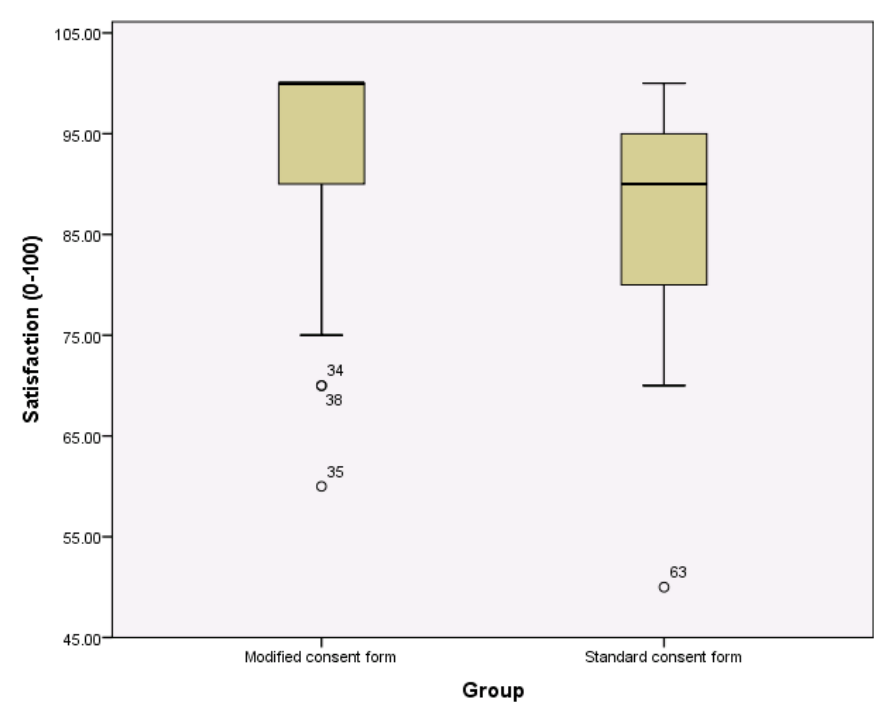

Figure 3. This figure illustrates the difference in patient satisfaction with the consent process between the current Department of Health consent form and the modified consent form.

regard to the risks and benefits associated with their surgery [7]. It is not simply about getting the patient's signature at the end of the day. This process is an essential step in ensuring that patients' best interests are protected and that they are given the appropriate information on which to base their decision. Pre-written consent forms may improve the efficiency of the consent process whilst concurrently enhancing patient understanding.

This study highlights the importance of a pre-written consent form on information retention compared to hand-written forms. Our findings demonstrate that the provision of a clear and concise written explanation facilitates greater understanding by the patient than a handwritten form. The pre-printed consent form contains all the major pertinent information regarding the nature of the procedure, and its associated risks and benefits. This reduces the reliance upon the attending clinician to impart this information and standardises the dissemination of knowledge to the patient. Furthermore, the preprinted form has been carefully designed to use clear, lay terminology to maximise patient understanding and future iterations of the form may be further improved following feedback from patients. Whilst the clinician discussing the procedure with the patient will be experienced and well-informed, there will inevitably be some inter-patient variation in the explanation provided on the handwritten form.

In many circumstances, small complications such as chronic wound pain or numbness can be omitted easily during the consent process, leading to increased patient anxiety following surgery [8]. Our findings indicate that the use of a modified pre-printed consent form ensures that all relevant major or common complications are included during the surgical explanation, allowing consent to be provided in a truly informed manner. Previous studies also suggest that pre-printed consent forms that relay benefits and complications can avoid litigation for negligence during the consent process $[9,10]$. Importantly, errors made during the consent process are a major burden on NHS finances due to the frequency of claims issued for medical negligence, which is estimated to cost millions of pounds per year [10].

Whilst the reason for the described improvements in patient knowledge retention is not fully determined in this study, it may be influenced by the patient being able to revisit the form without such simple obstacles as legibility of the handwritten explanation. Due to the significance of our findings in this study, we intend to broaden the use of the pre-printed consent form into other cardiac surgical procedures to determine whether this effect can be achieved.

\section{Limitations}

This study is limited by the lack of patient profiling with regard to their educational and professional status, which may have a direct effect on their level of understanding and retention of knowledge. Furthermore, no direct comparison was made between the information relayed in the standard consent form and that expressed on the modified, pre-printed form.

\section{Conclusion}

Our study highlights the importance of a written explanation of the potential benefits and risks of the surgical procedure on the consent form. This encourages greater patient understanding, which aids in shared decision making between the surgical nursing team and patient. Standardisation of the consent procedure will also minimise variations in the provision of information between clinical staff. If the informed consent process is carried out properly, it not only serves to respect patient autonomy but also strengthens the patient-surgical team relationship [7].

\section{Conflict of interest}

None declared.

\section{Funding}

No direct funding was allocated for this study. 


\section{References}

1. Jefford M, Moore R (2008) Improvement of informed consent and the quality of consent documents. Lancet Oncol 9: 485-493. [Crossref]

2. Seeking patients' consent: The ethical considerations. London: General Medical Council; 1998.

3. Butow PN, Brown RF, Tattersall MH (2000) Ethics of clinical trials. N Engl J Med 342: 978. [Crossref]

4. Chandrasekharan DP, Taggart DP (2011) Informed consent for interventions in stable coronary artery disease: problems, etiologies, and solutions. Eur J Cardiothorac Surg 39: 912-917. [Crossref]

5. Larobina ME, Merry CJ, Negri JC, Pick AW (2007) Is informed consent in cardiac surgery and percutaneous coronary intervention achievable? ANZ J Surg 77: 530-534. [Crossref]
6. Price DD, McGrath PA, Rafii A, Buckingham B (1983) The validation of visual analogue scales as ratio scale measures for chronic and experimental pain. Pain 17: 45-56. [Crossref]

7. Childers R, Lipsett PA, Pawlik TM (2009) Informed consent and the surgeon. J Am Coll Surg 208: 627-634. [Crossref]

8. Carle C, Ashworth A, Roscoe A (2009) A survey of post-sternotomy chronic pain following cardiac surgery. Anaesthesia 64: 1387. [Crossref]

9. Uzzaman MM, Tayeh S, Sinha S, Ratnasingham K, Stoker DL (2011) Consenting practice for laparoscopic cholecystectomy - are we doing enough to warn patients about their operation? Int J Surg 9: 643-647. [Crossref]

10. Hoosein MM, Towse H, Conn G, Stoker DL (2008) Consenting practice for open inguinal hernia repairs - are we failing to warn patients of serious complications? Ann $R$ Coll Surg Engl 90: 643-646. [Crossref]

Copyright: (C2016 Krishnamoorthy B. This is an open-access article distributed under the terms of the Creative Commons Attribution License, which permits unrestricted use, distribution, and reproduction in any medium, provided the original author and source are credited. 